\title{
The impact of genetic counselling on females in fragile $\mathrm{X}$ families
}

\author{
Greta Curtis, Nick Dennis, James MacPherson
}

\begin{abstract}
We report a retrospective study over the period 1981-1992 of the reproductive histories of 27 women, from 21 families, who were known or possible fragile $X$ carriers. Eighteen women had cytogenetic and DNA linkage studies to establish their carrier risk. They subsequently received definitive carrier status information following the cloning of the gene in 1991. The remaining nine women had cytogenetic and mutation studies only. For 11 of the women their carrier risk was modified over the 11 year period.

The results suggest that these women at risk of having a son with fragile $X$ have carefully considered their reproductive choices. Three of the six women who were initially sterilised have had, or are awaiting, a reversal of sterilisation following clarification of their carrier status. There were 10 pregnancies to 10 women. Seven of the pregnancies were to women at "high" $(40-100 \%)$ risk of being a carrier, and in this group only one woman chose to continue the pregnancy without prenatal diagnosis. Three pregnancies were to women at "medium" or "low" (<39\%) risk of being a carrier. None of the three chose prenatal diagnosis and one affected male was born to this group.
\end{abstract}

( $(\mathcal{M}$ Med Genet 1994;31:950-952)

The fragile $\mathrm{X}$ syndrome is the commonest cause of inherited mental retardation and is the second most frequent identifiable cause of mental retardation after Down's syndrome. ${ }^{1}$ It affects 1 in 2610 males and is also responsible for mild to moderate mental retardation in 1 in 4221 females. ${ }^{23}$

In June 1991 it was shown that the mutation is caused by the amplification of a (CGG) trinucleotide repeat. ${ }^{45}$ The repeat sequence falls into three size categories. In the general population normal persons have a repeat size of between six and 54 CGG repeats. Moderate expansions of between 52-200 CGG repeats appear to be a premutation without clinical effects. The full mutation is characterised by expansions of more than 250 repeats. ${ }^{6}$ The transition from premutation to full mutation occurs only by transmission through a female. ${ }^{7}$ Identification of the gene causing the fragile $\mathrm{X}$ site now enables accurate carrier testing in fragile X families.

The first diagnosis of fragile $\mathrm{X}$ was made in
Wessex in 1981 . We then began to offer genetic counselling to his family members and subsequent families as further families were ascertained following diagnosis. Over the years the carrier risk of women from fragile $\mathrm{X}$ families may have been modified two or three times as a result of changing knowledge about the condition. They will have made decisions about their reproductive choices based on the carrier risk information that was given at a particular time. We report a retrospective study of the reproductive histories of 27 women from 21 families over the period of 1981-1992, who were known or possible fragile X carriers, and who were seen by our clinical genetics service.

\section{Subjects and methods}

Women were considered for the study if they were known or possible fragile $\mathrm{X}$ carriers, had been seen by us, and were of reproductive age. Forty-six women satisfied the criteria for the study and were invited to participate in the study by letter. There were 35 replies; six women chose not to participate in the study, five of whom were not carriers of fragile $X$, and two had moved away. Eleven women did not reply; four were carriers of the full mutation and had learning difficulties, and seven were not carriers. Twenty-seven women were interviewed at home by using a semi-structured in depth inteview (table).

Fifteen women were mothers of affected males with fragile $X$. Of the 15 , three were also sisters and four were also aunts. Five were sisters only and the remaining seven were second or third degree relatives of affected males with fragile $\mathrm{X}$.

\section{Results}

Fig 1 shows the risk modification of the 27 women throughout the three stages of risk estimation. At stage 1 risks were based only on

Examples of questions used for the semi-structured interviews. These questions were repeated for each contact with the department (that is, the cytogenetic results, the DNA linkage results, and the gene insert results)

(1) In what year were you first contacted by the department?

(2) Why were you contacted?

(3) What was the risk that you were given of being a carrier for fragile $\mathrm{X}$ ?

(4) How did you consider this risk? (high risk, low risk, or no risk of being a carrier)

(5) Did you regard the information that you received about fragile $\mathrm{X}$ adequate?

(6) At that time were you considering having children or more children?

(7) Did your risk of being a carrier for fragile $\mathrm{X}$ affect your decisions about having a family? If yes, how?

(8) Did your and your partner's opinions differ about having children? 


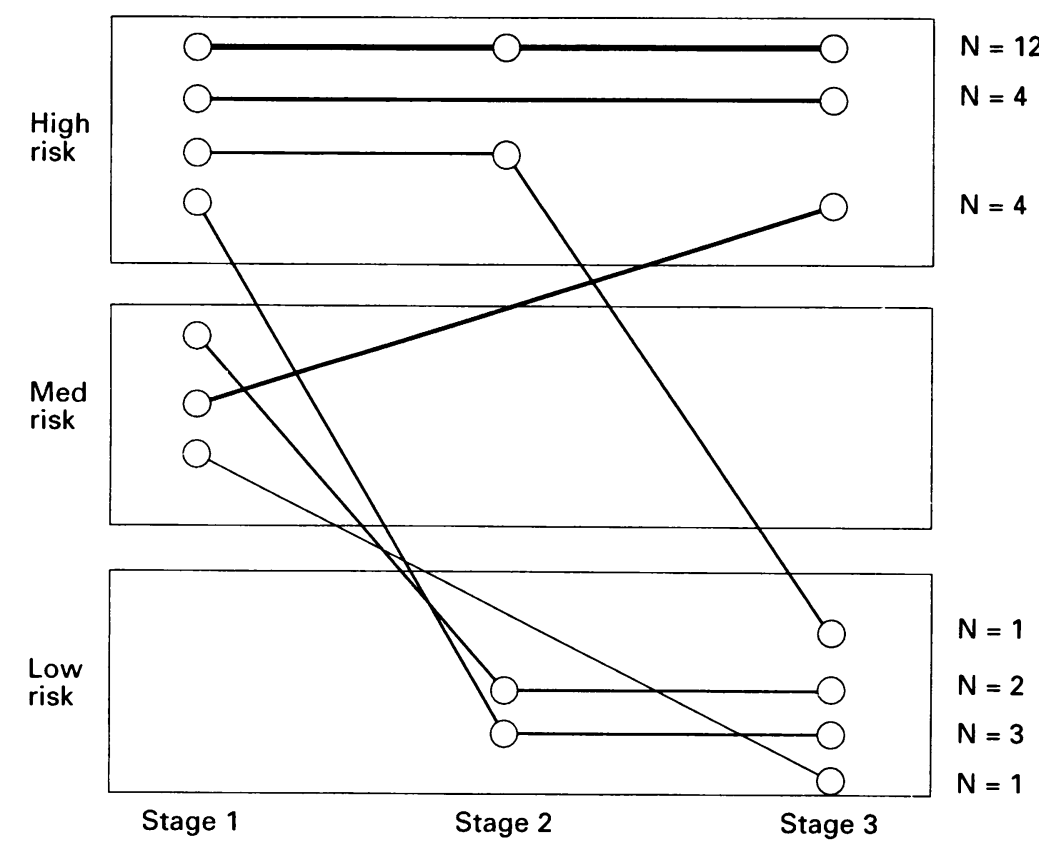

Figure 1 The risk modification of the 27 subjects through the three stages of risk estimation, and the number of women assigned to each risk group.

family history and cytogenetic analysis, at stage 2 the DNA linkage results were available, and at stage 3 direct mutational analysis gave definitive carrier status. On average each woman received two home visits, one clinic consultation, and three letters.

The risk of being a carrier (of a premutation or a full mutation) was defined as low $(0-10 \%$ risk), medium (11\%-39\% risk), and high ( $40 \%-100 \%$ risk). Fig 1 shows the risk modification of the 27 subjects through the three stages of counselling, and the number of women assigned to each risk group. At stage 3 there are only two groups, carriers and noncarriers. At stage 1, because of the inability of the cytogenetic analysis to exclude carrier status, no women were in the low risk group.

Sixteen women began with a high risk and have now been confirmed as carriers. One person who was given a high risk at stage 1 and stage 2 , has now been confirmed as a non- carrier. We now know that this discrepancy was because of a crossover affecting the linkage results. Three women who were initially given a high risk on pedigree grounds were shown to be non-carriers on linkage and mutation testing. Of the seven women initially in the medium risk category, four proved to be carriers and three non-carriers.

The recall of carrier risk information was compared with our records. When asked to recall carrier risk estimates that they were given, most women tried firstly to remember their chance of having an affected child. Only eight of the "high risk" group and two of the "medium risk" group remembered precise carrier risk figures. However, they were able to recall whether they were in a high or a low risk category.

Fig 2 shows the reproductive histories of the 27 women in the light of their risk status. Each person is identified as a number in brackets. There were seven pregnancies to women at "high" risk of being a carrier; four women (5, $6,20,19)$ took steps to avoid the birth of an affected son, and another (18) would have done so had the pregnancy been diagnosed earlier. Three pregnancies were to women $(24,26,27)$ at "medium" or "low" risk of being a carrier. None had prenatal diagnosis and one affected male was born to a woman (24) before mutation testing was available.

One women (12) was sterilised five weeks after the diagnosis of fragile $\mathrm{X}$ had been made in her son. She is now awaiting a reversal of sterilisation and wishes to have prenatal diagnosis when pregnant. When the diagnosis was made in the brother of one of the women (14), she chose to undergo a sterilisation. However, she has now had a reversal following confirmation by mutational analysis that she is not a carrier. Another woman (22) who was originally sterilised and has now been shown not to be a carrier is awaiting a reversal.

\section{Discussion}

Results from this preliminary study suggest that these women with a family history of fragile $\mathrm{X}$

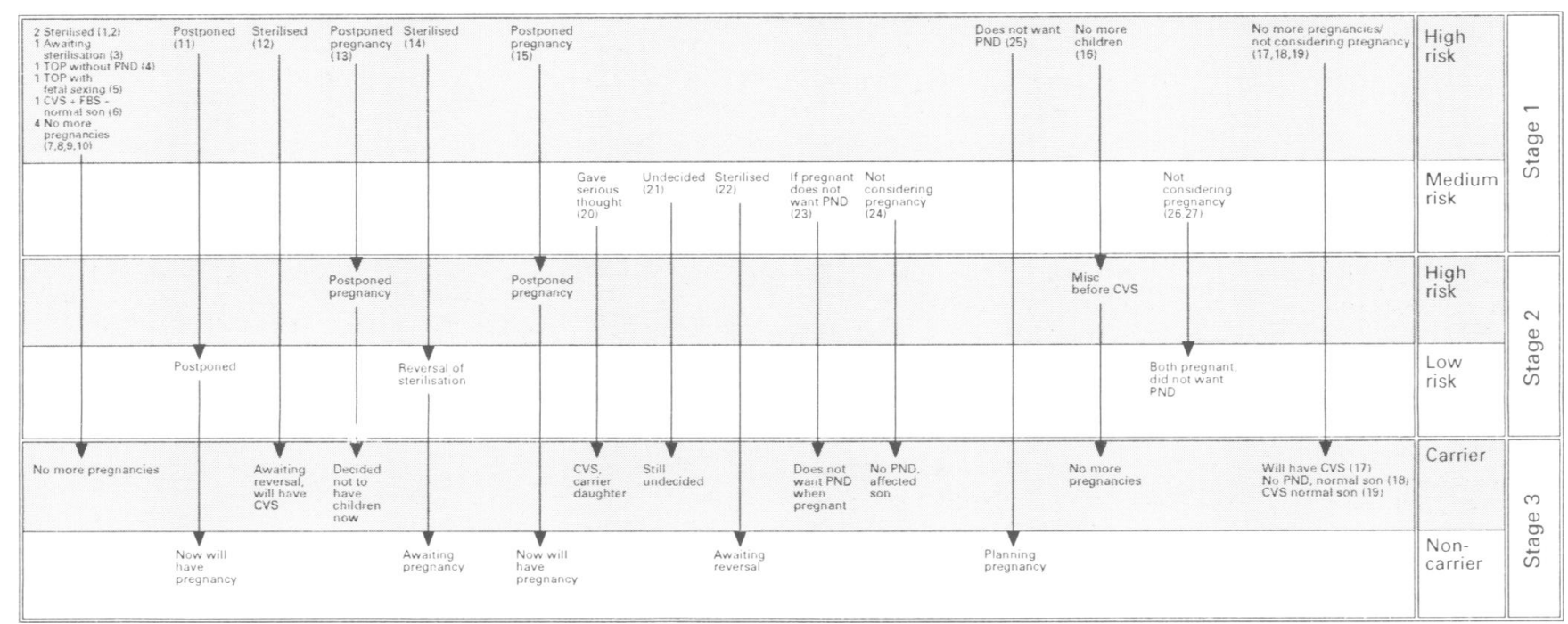

Figure 2 The reproductive histories of the 27 women corresponding to their carrier risk status. CVS=chorionic villus sampling; FBS =fetal blood sampling; $P N D=$ prenatal diagnosis; $T O P=$ termination of pregnancy; Misc = miscarriage. 
have carefully considered their reproductive choices. Six of the 27 women were initially sterilised, but now three have had, or are awaiting, a reversal of sterilisation. There were 10 pregnancies to 10 women, among whom only one who had been given a "high" carrier risk, chose to continue without prenatal diagnosis.

The proportion of carriers in the participating and non-participating groups was not significantly different. Therefore, we do not think that our study group was biased towards those at lower risk, although by the nature of the study they were self-selected for concern with genetic issues.

During our interviews with these women it was noticeable that they would have liked more information about the behavioural problems associated with fragile $\mathrm{X}$. Five mothers said that a referral to a psychologist might have given them useful guidance and information on how to manage the behavioural problems. This might then have improved their ability to cope with their children and given them more insight into the future lives of their children and their families. They reported that their decision to have or not to have more children would then have been a more informed one.

The recall of carrier risk estimates for fragile $\mathrm{X}$ was important to the women when considering their reproductive decisions. While they were unlikely to remember precise carrier risk figures, they did remember their risk of having an affected child. These results correspond to a previous study by D'Amico et $a l^{8}$ of women at high risk of a genetic disorder. The subjects translated their precise risk into personal and controllable information, that is, "I will or I will not have an affected child". Lippman-Hand and Fraser ${ }^{9}$ also showed that there was tendency to convert recurrence risks into "it will or won't happen". Statistical information is therefore transformed into more usable forms for the purpose of cognitive processing and decision making. ${ }^{10}$

The reproductive decision making process is not solely influenced by the magnitude of the risk (high versus low). Other factors are also taken into account, such as a previous personal experience of an affected child, and awareness of the "burden" of a possible new affected child ${ }^{8}$ Couples take risks even when the disease is perceived as being severe and prenatal diagnosis is not available. ${ }^{11}$

It appears from our study that we concentrated our efforts on the clients' understanding of the genetics of fragile $\mathrm{X}$, and perhaps to a degree neglected the clinical and psychological aspects of the disorder. Five of the mothers commented that the involvement of a psychologist might have been helpful for them. As a result of this study we have now formed a link with a local child psychologist to help these families.

In conclusion, although the results of this study are preliminary they provide some idea of how risks are perceived by women from families with fragile $\mathrm{X}$, and the decisions that are made concerning their reproductive choices.

We wish to thank Mrs Annette Dashwood for her help and patience in the typing of this manuscript.

1 Webb T, Bundey S, Thake A, et al. Population incidence and segregation ratios in the Martin-Bell syndrome. $A m$ f Med Genet 1986;23:573-80.

2 Turner G, Robinson H, Laing S, et al. Preventive screening for the fragile X syndrome. N Engl f Med 1986;315:607-9.

3 Turner G, Robinson H, Laing S, et al. Population screening for fragile X. Lancet 1992;325:1673-81.

4 Oberlé I, Rousseau F, Heitz D, et al. Instability of a 550 base pair DNA segment and abnormal methylation in fragile X syndrome. Science 1991;252:1097-102.

5 Yu S, Pritchard M, Kremer E, et al. Fragile X genotype characterized by an unstable region of DNA. Science 1991 ; 252:1179-81.

6 Heitz D, Devys D, Imbert G, et al. Inheritance of the fragile $\mathrm{X}$ syndrome: size of the fragile $\mathrm{X}$ premutation is a major determinant of the transition to full mutation. $\mathcal{F}$ Med Genet determinant of the

$7 \mathrm{Fu}$ YH, Kuhl DPA, Pizzuti A, et al. Variation of the CGG repeat at the fragile $X$ site results in genetic instability: resolution of the Sherman paradox. Cell 1991;67:1047-58

8 D'Amico R, Jacopini G, Vivona G, Frontali M. Reproductive choices in couples at risk for genetic disease: a qualitative and quantitative analysis. Birth Defects 1992;28(1):41-6.

9 Lippman-Hand A, Fraser FC. Genetic counselling - the postcounselling period. 1. Parent's perceptions of uncertainty. Am ₹्f Med Genet 1979;4:51-71.

10 Kessler S, Levine E. Psychological aspects of genetic counselling. IV. The subjective assessment of probability. $A m$ f Med Genet 1987;28:361-70.

11 Frets PG, Duivenvoorden HJ, Verhage F. Factors influencing the reproductive decision after genetic counselling. Am 7 Med Genet 1990;35:496-502. 